Research Article

\title{
Application of Interaction Effect Multichoice Goal Programming in Project Portfolio Analysis
}

\author{
Su-Lan Zhai, ${ }^{1}$ Xiao-Lan $\mathrm{Wu}^{2}$ Sheng-Yuan Wang $\mathbb{D}^{2},{ }^{2}$ and Tong Zhao ${ }^{2}$ \\ ${ }^{1}$ Department of Immunology, Nanjing Medical University, Nanjing, Jiangsu, China \\ ${ }^{2}$ Nanjing Xiaozhuang University, Nanjing, Jiangsu, China \\ Correspondence should be addressed to Sheng-Yuan Wang; 56439976@qq.com
}

Received 15 July 2021; Accepted 28 August 2021; Published 3 September 2021

Academic Editor: Anna M. Gil-Lafuente

Copyright (c) 2021 Su-Lan Zhai et al. This is an open access article distributed under the Creative Commons Attribution License, which permits unrestricted use, distribution, and reproduction in any medium, provided the original work is properly cited.

How to choose the optimal project portfolio based on the enterprise objectives is very important for the survival and development of an enterprise. However, the current portfolio analysis needs to be improved in the aspects of interaction effect analysis, multichoice target planning, and method simplicity and practicability. The method of portfolio selection proposed in this study takes into consideration the complex interaction within the portfolio, which makes up for the deficiency of the existing research on portfolio selection. This paper illustrates the application of the multichoice object programming method in the analysis of the combination of two-project and three-project interaction effects by a series of examples. The results show that the method is applicable in portfolio evaluation. The method of multichoice goal programming of the interaction effect provides the basis for enterprise to measure the complex relationship within the portfolio and also provides a new method and idea for the selection of the enterprise project portfolio.

\section{Introduction}

With the increasingly diversified market economy and increasingly fierce market competition, managers continue to expand the scope of business to improve the competitiveness of enterprises, and enterprise alternative projects are also expanding their scope. To maximize the overall benefit and obtain sustainable development of enterprises, the managers of enterprises need to choose the most suitable project portfolio in the multiproject environment with high complexity and strong dynamic. Therefore, it is very important to choose a portfolio in the process of enterprise portfolio management. Portfolio selection problem refers to the situation when the project management decision-maker selects a subset of projects from a limited set of alternative projects under the constraints of time, resources, cost, and other constraints and then forms a group that can achieve the desired and optimized organizational goals [1]. Portfolio selection is not only an important link in the process of organizing project management but also a part of strategic decision-making of enterprises. Successful portfolio selection can help enterprises effectively achieve organizational strategic objectives, improve the market competitiveness, and promote sustainable development of enterprises. Improper portfolio selection will not only increase the difficulty of project portfolio implementation and waste a large amount of resources but also reduce the competitive advantage, causing huge losses for enterprises. Therefore, how to choose the optimal project portfolio based on the enterprise objectives is very important for the survival and development of an enterprise.

However, owing to the wide range of enterprise management objectives, the complex interaction between different objectives, and the large number of enterprise alternative projects, there are resource, technology, and other related relationships among the projects. Therefore, how to choose the optimal project portfolio based on the enterprise objectives given the complex relationship between the projects and the strategic objectives has brought great challenges to the enterprise. Portfolio selection is the development and extension of project selection (PS) to meet the market requirements, and it is an important part of portfolio management. In the process of portfolio selection, decision-makers of organizations need to consider the constraints of resources, time, cost, and other conditions in addition to using the project research method to evaluate 
and sort projects and then select a subset of projects from the alternative pool to form a portfolio so that the portfolio can meet the constraints and achieve the goal expected by decision-makers: the optimal organization goal [2].

The research on portfolio selection originated from the modern portfolio theory put forward by Markowitz in 1952, which was initially applied mainly in the field of investment [3]. With the further research on the project portfolio, Lorie and Savage extended the project portfolio theory to the field of project management [4]. As an important part of project portfolio management, portfolio selection has been widely concerned by scholars. The research on portfolio selection mainly focuses on the evaluation of portfolio selection and the construction of the portfolio selection model. In the aspect of portfolio selection and evaluation, some scholars are committed to building a scientifically reasonable portfolio selection and evaluation framework from different perspectives. Modern project portfolio selection should consider its cyclical characteristics from a dynamic perspective to meet the short-term and long-term strategic objectives of the organization. Portfolio selection is a classical combinatorial optimization (CO) issue [5]. For example, Santhanam and Kyparisis [6] aimed at the interaction between technology and revenue among projects; Jin and Kim [7] combined it with the multiobjective characteristics of portfolio selection; Badri and Davis [8] considered the preference information of decision-makers and improved the basic model. In addition, some scholars used the classical fuzzy theory [9], system dynamics [10], and other theories to construct the multistage portfolio selection problem under the fuzzy situation.

The research goal of project portfolio selection based on interaction effect (IE) is to maximize the contribution of project portfolio to the realization of organizational strategy by selecting appropriate projects from alternative projects and combining them under the premise of fully considering the interaction between projects. From the perspective of the number of projects with interaction relationship, Czajkowski and Jones [11], Schmidt [12], Dickinson, and other scholars have conducted quantitative research on the interaction effect between projects in different years; however, the main problem of the models proposed in these studies is that they only conducted quantitative analysis on the interaction relationship between two projects. The fact is that in the past few years, many scholars have tried to quantify it, but their researches are all improvements on the classical interaction effect formula.

At present, there are three types of interaction effect models. In the first model, only two-way interaction is considered. For example, the model proposed by Czajkowski and Jones [11] and Schmidt [12] only considers the interaction between two projects. Then, Santhanam and Kyparisis [6] put forward an interactive project selection model with three projects in 1995, which was widely used by Jin and Kim [7], Jin and Kim [13], and Klapka and Piños [14]. In the second model, there is no restriction on the items with interaction relationship. This model is proposed by Santhanam and Kyparisis [15] based on the polynomial model. This paper assumes that there are different project groups, and each group contains at least four projects and produces additional contributions. The third model is proposed by Stummer and Heidenberger [16], which is improved based on the previous model and is thus more universal. This model is an extension of the one proposed by Santhanam and Kyparisis [6]. This model was adopted by Doerner et al. [17] and other scholars and can be used when all the alternative projects are implemented at the same time.

As an important part of project portfolio management, portfolio selection and optimization has gained attention from many scholars for a long time. Eilat et al. [18] used data envelopment analysis (DEA) in the evaluation of the interaction effect portfolio. Dickinson et al. [19] solved the portfolio selection optimization problem under uncertainty by introducing interval valued fuzzy (IVF). Carazo [2] used scatter search for the project portfolio selection (SS-PPS) mathematical method to solve the problem of portfolio selection and planning and carried out empirical verification. Stewart [20] proposed multiobjective portfolio selection based on the reference point. In recent years, the research of interaction effect project portfolio selection (IE-PPS) has achieved good results. However, owing to the complexity of model construction and solution technology, the basic model of IE-PPS involves less research on multiproject interaction, and the improved model only considers the situation where the interaction effect exists between two projects; in the dynamic perspective, the start and end time of the project is restricted; whether resources can be transferred is limited; thus, the gap between the model and the real solution environment has been enlarged; under the background of considering decision-maker's preference, it usually appears as a reference value and is not fitted in the solving model.

As a complex decision support system, the complexity of IE-PPS will increase geometrically along with the number of subprojects. Throughout the existing IE-PPS research, we need to face the following challenges: the final result of the portfolio selection problem is to provide decision support tools for project managers; therefore, the coupling of decision-maker's preference and portfolio problem has become a challenge of this research. How to give the appropriate portfolio selection solution from the perspective of decisionmaker and guide decision-maker to make the right choice is another challenge of this research. In the research process of portfolio selection based on the interaction effect, the research of project selection should also be included. Taking the key success factors as the measurement tool of project selection, we first make an early evaluation of the project itself, then use the project portfolio selection method on the basis of the interaction effect, which can help obtain the results of project portfolio selection by combining theory with practice, and finally make the research integrated.

The research motivation of this study is to develop a new portfolio evaluation method. This evaluation method should accurately measure the interaction effects between projects and their impact on the overall portfolio. To solve the above problems, this study set the following research objectives: to improve the existing evaluation model and to construct a portfolio selection evaluation model, which can solve the problem caused by the interaction effect. In this paper, the interaction effect relationship is embedded into the 
multichoice goal programming model (MCGP) to construct the multiobjective optimization model of portfolio selection. Then, a series of examples are given to verify the practicability and advanced nature of the model.

\section{Materials and Methods}

This paper illustrates the application of the MCGP method in the analysis of the combination of two-project and threeproject interaction effects by a series of examples.

2.1. Interaction Effect MCGP. With the increase of the number of alternative projects, it is found that when some projects are executed at the same time, they will have a dependency relationship and can influence each other in one or more dimensions, such as resources, benefits, risks, and so on; that is to say, it will lead to the collaborative results of projects in one or more dimensions, and these projects are considered interactive. The interaction between projects or between the project and project portfolio increases the uncertainty of enterprise project selection decision. Identifying the interaction effect brought by this interaction relationship will provide strong support for enterprises to the realization of the optimal allocation of resources and the control of risks.

Some scholars have pointed out that the interaction between projects should be considered in project selection decision-making when project selection still relies on a single indicator for decision-making [21, 22]. However, it was not until the 1980s that scholars did bring the interaction between projects into the research system. In 1980, Gear and Cowie [23] pointed out that there may be an internal interaction effect between projects, that is, the demand for resources or benefits of a project will affect whether other projects are selected. In addition, there is an interaction relationship between the project and the external environment, and the interaction between the internal and external factors will affect whether the project is selected. Bard et al. [24] pointed out that the interaction between projects and the ongoing project portfolio should be paid attention to in the project portfolio management. After that, some scholars have gradually noticed the importance of the relationship between projects for the project portfolio management and have tried to measure the interaction effect between projects from different angles.
There are several characteristics of the interaction effect between projects: the subjects involved are both projects and the project portfolio. Two or more subjects are involved. The root causes of the interaction effect between projects are as follows: the diversification strategy of enterprises requires the implementation of multiple projects at the same time and the project presents a variety of relationships such as competition and coordination on the production factors represented by resources. The characteristics of product development process and the logical relationship of project implementation lead to the interaction of project in the dimensions of knowledge and technology. The quantitative calculation of the interaction effect between projects can be obtained by solving resource interaction, revenue interaction, and technology interaction. However, with the increase of the number of interaction projects, the solution of interaction effect becomes more complex and the uncertainty of interaction effect on organization also increases. The interaction effect between projects may be "positive" or "negative," that is, the interaction effect between projects is directional. In a group of interactive projects, the interaction effect of project $A$ on project $B$ is not equal to that of project $\mathrm{B}$ on project $\mathrm{A}$. The interaction effect of the project portfolio is the sum of the interaction effects of related projects in different dimensions. Considering the interaction effect between projects is helpful for the organization to predict the follow-up results of a decision, which makes the decision more forward-looking.

To reflect the resource interaction and revenue interaction in the model, the objective function and constraints need to reflect some additional instructions. For example, the total contribution is equal to the sum of the respective contributions of the candidate projects plus or minus the additional contributions due to interaction, as shown in equation (1).

$$
Z\left(x_{1}, x_{2}, \ldots, x_{n}\right)=c_{1} x_{1}+c_{2} x_{2}+\cdots c_{n} x_{n}+y\left(x_{1}, x_{2}, \ldots, x_{n}\right),
$$

where $c_{q}$ represents the independent distribution of the $q$-th item and $y$ represents the algebraic sum of additional items due to the interaction between items.

MCGP proposed by Chang $[25,26]$ has been widely used to resolve many practical decision-making problems in recent years $[27,28]$. The MCGP method is described as follows:

$$
\begin{aligned}
& \text { Objective function: } \operatorname{Min} \sum_{i=1}^{n}\left(d_{i}^{+}+d_{i}^{-}\right)+\sum_{i=1}^{n}\left(e_{i}^{+}+e_{i}^{-}\right) \\
& \text {Constraints: }\left\{\begin{array}{l}
f_{i}(x)-d_{i}^{+}+d_{i}^{-}=g_{i}, \quad i=1,2, \ldots, n \\
x \in X=\left\{x_{1}, x_{2}, \ldots, x_{n}\right\} \\
g_{i}-e_{i}^{+}+e_{i}^{-}=g_{i, \max }, \quad i=1,2, \ldots, n \\
g_{i, \min } \leq g_{i} \leq g_{i, \max }, \quad i=1,2, \ldots, n \\
d_{i}^{+}, d_{i}^{-}, e_{i}^{+}, e_{i}^{-} \geq 0, \quad i=1,2, \ldots, n \\
X \in F, \quad(F \text { is the set of feasible solutions }) .
\end{array}\right.
\end{aligned}
$$


Here, $d_{i}^{+}, d_{i}^{-}$indicates the value of the $i$-th goal exceeding and not reaching the expected value of the goal. $f_{i}(x)$ is the function of the $i$-th object. $X$ is the decision variable, representing $m$ alternatives $\left(x_{1}, x_{2}, \ldots, x_{m}\right) . g_{i}$ is the expected level for the $i$-th goal. $e_{i}^{+}$and $e_{i}^{-}$are close to positive and negative deviation variables of $\left|g_{i}-g_{i, \max }\right|$, respectively. $g_{i, \min }$ and $g_{i, \max }$ are the lower and upper limits of the target for $g_{i}$, respectively.

Considering the symbiotic relationship [29, 30], new constraints need to be added to the above model:

$$
\begin{aligned}
& \text { Objective function: } \operatorname{Min} \sum_{i=1}^{n}\left(d_{i}^{+}+d_{i}^{-}\right)+\sum_{i=1}^{n}\left(e_{i}^{+}+e_{i}^{-}\right) \\
& \text {Constraints: }\left\{\begin{array}{l}
f_{i}(x)-d_{i}^{+}+d_{i}^{-}=g_{i}, \quad i=1,2, \ldots, n \\
x \in X=\left\{x_{1}, x_{2}, \ldots, x_{n}\right\} \\
g_{i}-e_{i}^{+}+e_{i}^{-}=g_{i, \max }, \quad i=1,2, \ldots, n \\
g_{i, \min } \leq g_{i} \leq g_{i, \max }, \quad i=1,2, \ldots, n \\
d_{i}^{+}, d_{i}^{-}, e_{i}^{+}, e_{i}^{-} \geq 0, \quad i=1,2, \ldots, n \\
X \in F, \quad(F \text { is the set of feasible solutions }) \\
Z\left(x_{1}, x_{2}, \ldots, x_{n}\right)=c_{1} x_{1}+c_{2} x_{2}+\cdots c_{n} x_{n}+y\left(x_{1}, x_{2}, \ldots, x_{n}\right) .
\end{array}\right.
\end{aligned}
$$

The problem is solved using the LINGO [31] software.

2.2. Two Sample Project Portfolios. This example evaluates the project portfolio from the scenarios of a single-objective, multiple objectives, a two-project portfolio, and a threeproject portfolio. First, this paper gives an example of singleobjective portfolio analysis. This paper takes a company's portfolio management process as an example to verify the effectiveness of the proposed portfolio allocation evaluation model. According to the company's basic strategic objectives, two projects are selected from the four alternative projects to be implemented to form the optimal project portfolio so as to achieve the business objectives of two projects simultaneously, and the higher the income, the better.

The characteristic attributes of investment projects can be expressed using formula (4):

$$
P_{i}: Y_{i}=a x_{i}-b \text {, }
$$

where $P_{i}$ represents the $i$-th project and $Y_{i}$ represents the total income of the project (unit: 10,000 yuan). $X_{i}$ refers to the investment in the operation period of the project (unit: 10,000 yuan). $B$ refers to the investment in the construction period of the project (unit: 10,000 yuan). $A$ is the profit coefficient of the operation period of the project. The properties of the four basic investment projects are as follows:

$$
\begin{aligned}
& P_{1}: Y_{1}=0.56 x_{1}-17600 \\
& P_{2}: Y_{2}=0.66 x_{2}-25000 \\
& P_{3}: Y_{3}=0.70 x_{3}-15800 \\
& P_{4}: Y_{4}=0.58 x_{4}-24000
\end{aligned}
$$

First, this example evaluates the single-factor project portfolio. In the evaluation of a single-factor project portfolio, the income level of the project portfolio is mainly considered. The bigger the portfolio, the better. Without considering the interaction effect, the six project portfolios have the following characteristics:

$$
\begin{aligned}
& P P_{1}: Y_{1}+Y_{2}=0.56 x_{1}-17600+0.66 x_{2}-25000 \\
& P P_{2}: Y_{1}+Y_{3}=0.56 x_{1}-17600+0.70 x_{3}-15800 \\
& P P_{3}: Y_{1}+Y_{4}=0.56 x_{1}-17600+0.58 x_{4}-24000 \\
& P P_{4}: Y_{2}+Y_{3}=0.66 x_{2}-25000+0.70 x_{3}-15800 \\
& P P_{5}: Y_{2}+Y_{4}=0.66 x_{2}-25000+0.58 x_{4}-24000 \\
& P P_{6}: Y_{3}+Y_{4}=0.70 x_{3}-15800+0.58 x_{4}-24000
\end{aligned}
$$

When considering the interaction effect between the returns of a single project, the six project portfolios have the following attributes:

$$
\begin{aligned}
& P P_{1}: Y_{1}+Y_{2}=0.56 x_{1}-17600+0.66 x_{2}-25000+(8.10 \times \\
& \left.10^{-7}\right) x_{1} x_{2} \\
& P P_{2}: \quad Y_{1}+Y_{3}=0.56 x_{1}-17600+0.70 x_{3}-15800+ \\
& \left(-1.22 \times 10^{-6}\right) x_{1} x_{3} \\
& P P_{3}: \quad Y_{1}+Y_{4}=0.56 x_{1}-17600 \quad+0.58 x_{4}-24000+ \\
& \left(-6.30 \times 10^{-7}\right) x_{1} x_{4} \\
& P P_{4}: \quad Y_{2}+Y_{3}=0.66 x_{2}-25000+0.70 x_{3}-15800+ \\
& \left(9.40 \times 10^{-7}\right) x_{2} x_{3} \\
& P P_{5}: Y_{2}+Y_{4}=0.66 x_{2}-25000+0.58 x_{4}-24000+(1.93 \times \\
& \left.10^{-6}\right) x_{2} x_{4} \\
& P P_{6}: Y_{3}+Y_{4}=0.70 x_{3}-15800+0.58 x_{4}-24000+(7.90 \times \\
& \left.10^{-7}\right) x_{3} x_{4}
\end{aligned}
$$

As shown in Table 1, whether the interaction effect is considered or not has an important impact on the evaluation of project portfolio. In this case, when the interaction effect is not considered, $\mathrm{PP}_{2}$ has the best return. After adding the influence of interaction effect, the income of $P P_{2}$ ranked second in the alternatives and the income of $P_{4}$ ranked first. This example shows that the interaction effects between projects need to be considered in portfolio evaluation. 


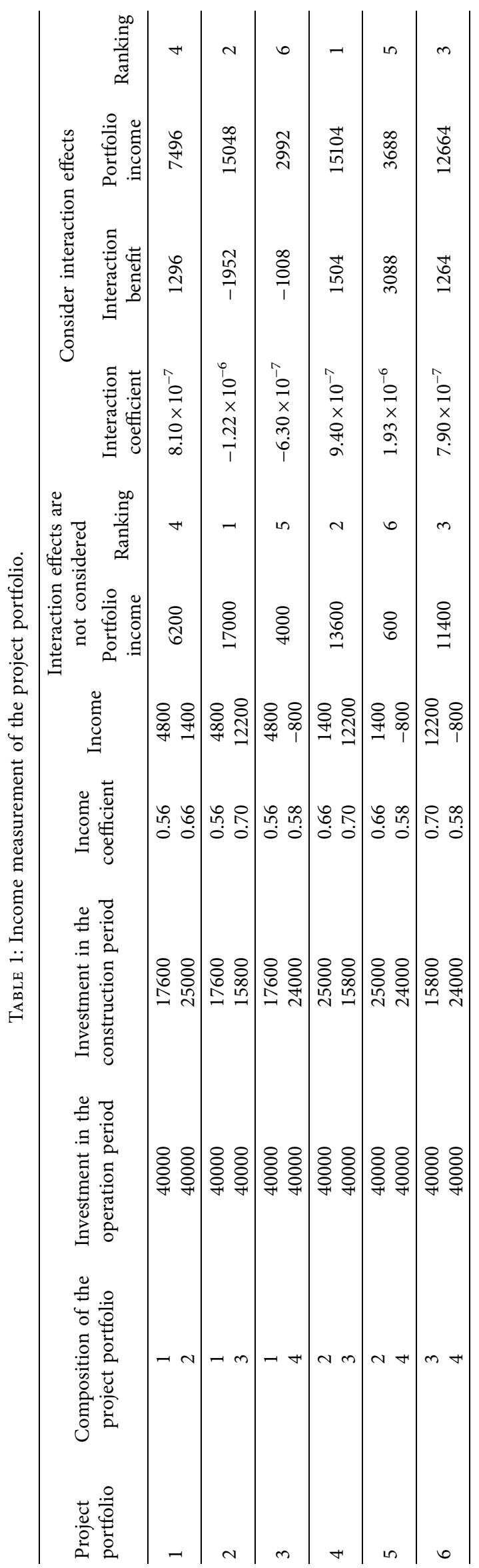


As shown in Table 2, the project portfolio evaluation method based on the optimization results of the MCGP model is obviously different from the simple project portfolio evaluation method. MCGP can analyze data better and deal with problems that cannot be solved by traditional methods. To sum up, the method proposed in this paper is effective in a single goal situation. Now, we will do an example analysis in the multiobjective situation. In the above example, the constraint target of the number of personnel is added. Different investment projects require a different number of employees. Suppose that the number of employees $\left(M_{i}\right)$ of a single project $\left(P_{i}\right)$ is as follows:

$$
\begin{aligned}
& P_{1}: M_{1}=0.02 x_{1} \text { (Unit: person) } \\
& P_{2}: M_{2}=0.01 x_{2} \text { (Unit: person) } \\
& P_{3}: M_{3}=0.03 x_{3} \text { (Unit: person) } \\
& P_{4}: M_{4}=0.01 x_{4} \text { (Unit: person) }
\end{aligned}
$$

The total number of employees in the project portfolio should not exceed 1,200, and the number of individual employees should exceed 200 . Owing to the simplicity of the example analysis, this paper does not consider the interaction effect of project personnel requirements. In this case, the investment in the operation period of the project portfolio is not more than 80 million yuan. Therefore, the constraints of different project portfolios are as follows:

$$
\begin{aligned}
& P P_{1}: Y_{1}+Y_{2}=0.56 x_{1}-17600+0.66 x_{2}-25000+(8.10 \times \\
& \left.10^{-7}\right) x_{1} x_{2} \\
& x_{1}+x_{2} \leq 80000 ; \\
& M_{1}+M_{2}=0.02 x_{1}+0.01 \times 2, M_{1}+M_{2} \leq 1200, M_{1} \geq 200, \\
& M_{2} \geq 200 ; \\
& P P_{2}: \quad Y_{1}+Y_{3}=0.56 x_{1}-17600+0.70 x_{3}-15800+ \\
& \left(-1.22 \times 10^{-6}\right) x_{1} x_{3} ; \\
& x_{1}+x_{3} \leq 80000 \\
& M_{1}+M_{3}=0.02 x_{1}+0.03 x_{3}, \quad M_{1}+M_{3} \leq 1200, \quad M_{1} \geq 200, \\
& M_{3} \geq 200 \\
& P P_{3}: \\
& \left(-6.30 \times 10^{-7}\right) x_{1} x_{4}=0.56 x_{1}-17600+0.58 x_{4}-24000+ \\
& x_{1}+x_{4} \leq 80000 \\
& M_{1}+M_{4}=0.02 x_{1}+0.01 x_{4}, \quad M_{1}+M_{4} \leq 1200, \quad M_{1} \geq 200, \\
& M_{4} \geq 200 \\
& P P_{4}: Y_{2}+Y_{3}=0.66 x_{2}-25000+0.70 x_{3}-15800+(9.40 \times \\
& \left.10^{-7}\right) x_{2} x_{3} \\
& x_{2}+x_{3} \leq 80000 \\
& M_{2}+M_{3}=0.02 x_{2}+0.03 x_{3}, \quad M_{2}+M_{3} \leq 1200, \quad M_{2} \geq 200, \\
& M_{3} \geq 200 \\
& P P_{5}: Y_{2}+Y_{4}=0.66 x_{2}-25000+0.58 x_{4}-24000+(1.93 \times \\
& \left.10^{-6}\right) x_{2} x_{4} \\
& x_{2}+x_{4} \leq 80000 \\
& M_{2}+M_{4}=0.01 x_{2}+0.01 x_{4}, \quad M_{2}+M_{4} \leq 1200, \quad M_{2} \geq 200, \\
& M_{4} \geq 200 \\
& P P_{6}: Y_{3}+Y_{4}=0.70 x_{3}-15800+0.58 x_{4}-24000+(7.90 \times \\
& \left.10^{-7}\right) x_{3} x_{4} \\
& x_{3}+x_{4} \leq 80000
\end{aligned}
$$

$$
\begin{aligned}
& M_{3}+M_{4}=0.03 x_{3}+0.01 x_{4}, \quad M_{3}+M_{4} \leq 1200, \quad M_{3} \geq 200, \\
& M_{4} \geq 200
\end{aligned}
$$

As shown in Table 3, after the personnel arrangement is added to the evaluation objective of the project portfolio, the evaluation ranking of the project portfolio has changed significantly. This shows that the interaction effect MCGP model can deal with the multiobjective portfolio evaluation well. To compare the effect of multiobjective evaluation, this paper uses the DEA evaluation method for comparative analysis. The DEA method is also a common method for portfolio evaluation [18]. What is the difference between the DEA method and the interaction effect MCGP model in portfolio evaluation?

As shown in Table 4, this paper selects investment and the number of employees as input indicators and project portfolio income as output indicators. Before the operation, the data is normalized. The results of data envelopment analysis are shown in Table 5.

As shown in Table 5, the DEA method cannot distinguish the advantages and disadvantages of portfolio 5 and portfolio 6. Therefore, the interaction effect MCGP model is more effective in portfolio evaluation.

2.3. Three-Project Portfolio Examples. In this example, the total number of employees in the project portfolio is not more than 1200 and the number of individual employees is not less than 200. The investment in the operation period of the project portfolio shall not exceed 80,000. Therefore, the constraints of different project portfolios are as follows:

$$
\begin{aligned}
& P P_{1}^{\prime}: Y_{1}+Y_{2}+Y_{3}=0.56 x_{1}-17600+0.66 x_{2}-25000+ \\
& 0.70 x_{3}-15800+\left(-9.88 \times 10^{-12}\right) x_{1} x_{2} x_{3} \\
& x_{1}+x_{2}+x_{3} \leq 80000 \\
& M_{1}+M_{2}+M_{3}=0.02 x_{1}+0.01 x_{2}+0.03 x_{3}, \quad M_{1}+M_{2}+ \\
& M_{3} \leq 1200, M_{1} \geq 200, M_{2} \geq 200 ; M_{3} \geq 200 \\
& P P_{2}^{\prime}: Y_{1}+Y_{2}+Y_{4}=0.56 x_{1}-17600+0.66 x_{2}-25000+ \\
& 0.58 x_{4}-24000+\left(-1.22 \times 10^{-11}\right) x_{1} x_{2} x_{4} \\
& x_{1}+x_{2}+x_{4} \leq 80000 \\
& M_{1}+M_{2}+M_{4}=0.02 x_{1}+0.02 x_{2}+0.01 x_{4}, \quad M_{1}+M_{2}+ \\
& M_{4} \leq 1200, M_{1} \geq 200, M_{2} \geq 200 ; M_{4} \geq 200 \\
& P P_{3}^{\prime}: \quad Y_{1}+Y_{3}+Y_{4}=0.56 x_{1}-17600+0.70 x_{3}-15800+ \\
& 0.58 x_{4}-24000+\left(-9.64 \times 10^{-12}\right) x_{1} x_{3} x_{4} \\
& x_{1}+x_{3}+x_{4} \leq 80000 \\
& M_{1}+M_{3}+M_{4}=0.02 x_{1}+0.03 x_{3}+0.01 x_{4}, \\
& M_{1}+M_{3}+M_{4} \leq 1200, M_{1} \geq 200, M_{3} \geq 200 ; M_{4} \geq 200 \\
& P P_{4}^{\prime}: Y_{2}+Y_{3}+Y_{4}=0.66 x_{2}-25000+0.70 x_{3}-15800+ \\
& 0.58 x_{4}-24000+\left(7.43 \times 10^{-12}\right) x_{2} x_{3} x_{4} \\
& x_{2}+x_{3}+x_{4} \leq 80000 \\
& M_{2}+M_{3}+M_{4}=0.02 x_{2}+0.03 x_{3}+0.01 x_{4}, \\
& M_{4} \leq 1200, M_{2} \geq 200, M_{3} \geq 200 ; M_{4} \geq 200
\end{aligned}
$$

As shown in Table 6, this method can well distinguish the advantages and disadvantages of different project portfolios. Because of the strict resource constraints, the profit of different project combinations is less than zero. Therefore, we should increase the upper limit of resource constraints 
TABLE 2: Optimization results of the MCGP model for the project portfolio.

\begin{tabular}{|c|c|c|c|c|c|c|c|}
\hline $\begin{array}{l}\text { Project } \\
\text { portfolio }\end{array}$ & $\begin{array}{l}\text { Composition of the } \\
\text { project portfolio }\end{array}$ & $\begin{array}{l}\text { Investment in the } \\
\text { operation period }\end{array}$ & $\begin{array}{l}\text { Investment in the } \\
\text { construction period }\end{array}$ & $\begin{array}{l}\text { Income } \\
\text { coefficient }\end{array}$ & Income & $\begin{array}{l}\text { Portfolio } \\
\text { income }\end{array}$ & Ranking \\
\hline \multirow{2}{*}{1} & 1 & 10000 & 17600 & 0.56 & -12000 & \multirow{2}{*}{9767} & \multirow{2}{*}{4} \\
\hline & 2 & 70000 & 25000 & 0.66 & 21200 & & \\
\hline \multirow{2}{*}{2} & 1 & 10000 & 17600 & 0.56 & -12000 & \multirow[b]{2}{*}{20346} & \multirow{2}{*}{1} \\
\hline & 3 & 70000 & 15800 & 0.70 & 33200 & & \\
\hline \multirow[b]{2}{*}{3} & 1 & 70000 & 17600 & 0.56 & 21600 & \multirow[b]{2}{*}{2959} & \multirow[b]{2}{*}{6} \\
\hline & 4 & 10000 & 24000 & 0.58 & -18200 & & \\
\hline \multirow{2}{*}{4} & 2 & 18723 & 25000 & 0.66 & -12643 & \multirow[b]{2}{*}{15529} & \multirow[b]{2}{*}{3} \\
\hline & 3 & 61276 & 15800 & 0.70 & 27093 & & \\
\hline \multirow{2}{*}{5} & 2 & 60725 & 25000 & 0.66 & 15079 & \multirow{2}{*}{4516} & \multirow{2}{*}{5} \\
\hline & 4 & 19274 & 24000 & 0.58 & -12821 & & \\
\hline \multirow{2}{*}{6} & 3 & 70000 & 15800 & 0.70 & 33200 & \multirow{2}{*}{15553} & \multirow[b]{2}{*}{2} \\
\hline & 4 & 10000 & 24000 & 0.58 & -18200 & & \\
\hline
\end{tabular}

TABLE 3: Optimization results of the MCGP model for the interaction effect of the project portfolio.

\begin{tabular}{|c|c|c|c|c|c|c|c|c|}
\hline $\begin{array}{l}\text { Project } \\
\text { portfolio }\end{array}$ & $\begin{array}{l}\text { Composition of the } \\
\text { project portfolio }\end{array}$ & $\begin{array}{l}\text { Investment in the } \\
\text { operation period }\end{array}$ & $\begin{array}{l}\text { Investment in the } \\
\text { construction period }\end{array}$ & $\begin{array}{l}\text { Income } \\
\text { coefficient }\end{array}$ & Income & $\begin{array}{c}\text { Portfolio } \\
\text { income }\end{array}$ & $\begin{array}{l}\text { Number of } \\
\text { employees }\end{array}$ & Ranking \\
\hline \multirow{2}{*}{1} & 1 & 40000 & 17600 & 0.56 & 4800 & \multirow[b]{2}{*}{7496} & 1000 & \multirow{2}{*}{2} \\
\hline & 2 & 40000 & 25000 & 0.66 & 1400 & & 200 & \\
\hline \multirow[b]{2}{*}{2} & 1 & 45000 & 17600 & 0.56 & 7600 & \multirow[b]{2}{*}{-1749} & 1000 & \multirow{2}{*}{6} \\
\hline & 3 & 10000 & 15800 & 0.70 & -8800 & & 200 & \\
\hline \multirow{2}{*}{3} & 1 & 10000 & 17600 & 0.56 & -12000 & \multirow{2}{*}{4159} & 700 & \multirow{2}{*}{4} \\
\hline & 4 & 70000 & 24000 & 0.58 & 16600 & & 200 & \\
\hline \multirow[b]{2}{*}{4} & 2 & 50493 & 25000 & 0.66 & 8325 & \multirow{2}{*}{0} & 200 & \multirow{2}{*}{5} \\
\hline & 3 & 10000 & 15800 & 0.70 & -8800 & & 1000 & \\
\hline \multirow{2}{*}{5} & 2 & 60725 & 25000 & 0.66 & 15079 & \multirow{2}{*}{4516} & 600 & \multirow[b]{2}{*}{3} \\
\hline & 4 & 19274 & 24000 & 0.58 & -12821 & & 200 & \\
\hline \multirow{2}{*}{6} & 3 & 20000 & 15800 & 0.70 & -1800 & \multirow{2}{*}{9948} & 1000 & \multirow[b]{2}{*}{1} \\
\hline & 4 & 60000 & 24000 & 0.58 & 10800 & & 200 & \\
\hline
\end{tabular}

TABLE 4: Input output data of the project portfolio.

\begin{tabular}{lccc}
\hline Project portfolio & $\begin{array}{c}\text { Output } \\
\text { Portfolio income }\end{array}$ & Input \\
\hline 1 & 7496 & 122600 & Total investment \\
2 & -1749 & 88400 & 1200 \\
3 & 4159 & 121600 & 900 \\
4 & 0 & 101293 & 1200 \\
5 & 4516 & 128999 & 800 \\
6 & 9948 & 119800 & 1200 \\
\hline
\end{tabular}

TABLE 5: DEA results of the project portfolio.

\begin{tabular}{llll}
\hline Project portfolio $\left(P P_{i}\right)$ & Crste & Vrste & Scale \\
\hline 1 & 0.762 & 0.836 & 0.911 \\
2 & 0.000 & 1.000 & 0.000 \\
3 & 0.863 & 1.000 & 0.863 \\
4 & 0.365 & 0.773 & 0.472 \\
5 & 1.000 & 1.000 & 1.000 \\
6 & 1.000 & 1.000 & 1.000 \\
Mean & 0.662 & 0.935 & 0.708 \\
\hline
\end{tabular}

crste $=$ technical efficiency from CRS DEA, vrste $=$ technical efficiency from VRS DEA, scale $=$ scale efficiency $=$ crste/vrste. 
TABLE 6: Three-project portfolio evaluation results.

\begin{tabular}{|c|c|c|c|c|c|c|}
\hline $\begin{array}{l}\text { Project } \\
\text { portfolio }\end{array}$ & Ranking & $\begin{array}{l}\text { Composition of the } \\
\text { project portfolio }\end{array}$ & $\begin{array}{l}\text { Investment in the } \\
\text { operation period }\end{array}$ & $\begin{array}{l}\text { Investment in the } \\
\text { construction period }\end{array}$ & $\begin{array}{l}\text { Number of } \\
\text { employees }\end{array}$ & $\begin{array}{c}\text { Portfolio } \\
\text { income }\end{array}$ \\
\hline \multirow{3}{*}{1} & \multirow{3}{*}{1} & 1 & 10000 & 17600 & 800 & \multirow{3}{*}{-6082} \\
\hline & & 2 & 55000 & 25000 & 200 & \\
\hline & & 3 & 15000 & 15800 & 200 & \\
\hline \multirow{3}{*}{2} & \multirow{3}{*}{4} & 1 & 10000 & 17600 & 500 & \multirow{3}{*}{-15673} \\
\hline & & 2 & 60000 & 25000 & 200 & \\
\hline & & 4 & 10000 & 24000 & 200 & \\
\hline \multirow{3}{*}{3} & \multirow{3}{*}{2} & 1 & 10000 & 17600 & 800 & \multirow{3}{*}{-9480} \\
\hline & & 3 & 15000 & 15800 & 200 & \\
\hline & & 4 & 55000 & 24000 & 200 & \\
\hline \multirow{3}{*}{4} & \multirow{3}{*}{3} & 2 & 20000 & 25000 & 800 & \multirow{3}{*}{-15526} \\
\hline & & 3 & 10000 & 15800 & 200 & \\
\hline & & 4 & 50000 & 24000 & 200 & \\
\hline
\end{tabular}

when evaluating similar portfolio problems. The total number of employees in our project portfolio is no more than 1800 , and the number of individual employees is no less than 200. The investment in the operation period of the project portfolio shall not exceed 120,000. Therefore, the constraints of different project portfolios are as follows:

$$
\begin{aligned}
& P P_{1}^{\prime}: \quad Y_{1}+Y_{2}+Y_{3}=0.56 x_{1}-17600+0.66 x_{2}-25000+ \\
& 0.70 x_{3}-15800+\left(-9.88 \times 10^{-12}\right) x_{1} x_{2} x_{3} \\
& x_{1}+x_{2}+x_{3} \leq 120000 \\
& M_{1}+M_{2}+M_{3}=0.02 x_{1}+0.01 x_{2}+0.03 x_{3}, \\
& M_{1}+M_{2}+M_{3} \leq 1800, M_{1} \geq 200, M_{2} \geq 200 ; M_{3} \geq 200 \\
& P P_{2}^{\prime}: \quad Y_{1}+Y_{2}+Y_{4}=0.56 x_{1}-17600+0.66 x_{2}-25000+ \\
& 0.58 x_{4}-24000+\left(-1.22 \times 10^{-11}\right) x_{1} x_{2} x_{4} \\
& x_{1}+x_{2}+x_{4} \leq 120000 \\
& M_{1}+M_{2}+M_{4}=0.02 x_{1}+0.02 x_{2}+0.01 x_{4}, \quad M_{1}+M_{2}+ \\
& M_{4} \leq 1800, M_{1} \geq 200, M_{2} \geq 200 ; M_{4} \geq 200 \\
& P P_{3}^{\prime}: \quad Y_{1}+Y_{3}+Y_{4}=0.56 x_{1}-17600+0.70 x_{3}-15800+ \\
& 0.58 x_{4}-24000+\left(-9.64 \times 10^{-12}\right) x_{1} x_{3} x_{4} \\
& x_{1}+x_{3}+x_{4} \leq 120000 \\
& M_{1}+M_{3}+M_{4}=0.02 x_{1}+0.03 x_{3}+0.01 x_{4}, \\
& M_{1}+M_{3}+M_{4} \leq 1800, M_{1} \geq 200, M_{3} \geq 200 ; M_{4} \geq 200 \\
& P P_{4}^{\prime}: \quad Y_{2}+Y_{3}+Y_{4}=0.66 x_{2}-25000+0.70 x_{3}-15800+ \\
& 0.58 x_{4}-24000+\left(7.43 \times 10^{-12}\right) x_{2} x_{3} x_{4} \\
& x_{2}+x_{3}+x_{4} \leq 120000 \\
& M_{2}+M_{3}+M_{4}=0.02 x_{2}+0.03 x_{3}+0.01 x_{4}, \\
& M_{2}+M_{3}+M_{4} \leq 1800, M_{2} \geq 200, M_{3} \geq 200 ; M_{4} \geq 200
\end{aligned}
$$

As shown in Table 7, when the total resources of the project portfolio are sufficient, the income of the project portfolio is greater than zero. It can be seen that the interaction effect MCGP model is also very effective in the three-project portfolio evaluations.

\section{Results and Discussion}

As an effective method to achieve organizational strategic objectives, the project portfolio has been favored by many enterprises. As an important part of project portfolio management, project portfolio selection has an important impact on the successful implementation of project portfolio. With the increasingly fierce market competition and enterprises gradually expanding their business scope, the scope and number of alternative projects with complex relationship between each other are expanding and the organization has many strategic objectives. All these factors combined bring great challenges for the organization to choose a reasonable project portfolio. This study constructs a project portfolio selection model based on collaborative relationship, which provides a reference for enterprise project portfolio selection. The specific research contents of this study are summarized as follows: the project portfolio selection method considering collaborative relationship proposed in this study further improves and expands the project portfolio selection method and enriches the project portfolio management theory. It also provides a new perspective and ideas for enterprises to measure the collaborative relationship among the alternatives and select the optimal project portfolio. Compared with the fuzzy theory $[9,32,33]$ and system dynamics [10], this method is simpler and easier to operate. Compared with the DEA method [18], the method in this paper can distinguish better. Compared with the collaborative relationship project portfolio $[34,35]$, this method is more universal. Because the relationship between many projects is not necessarily collaborative, the interaction effect is more consistent with the description of the relationship between projects.

The theoretical contributions of this paper are mainly reflected as follows: (1) this paper expands the research perspective of portfolio evaluation and carries out portfolio analysis from the interaction effect between projects. (2) An effective model is developed to evaluate the interaction effects of projects and their impact on project portfolio. (3) A series of examples show the adaptability and effectiveness of the method. This paper has a wide range of industrial applications, such as product portfolio analysis, investment project portfolio research, innovation project evaluation, financial investment, and derivatives trading. 
TABLE 7: Evaluation results of three-project portfolios with sufficient resources.

\begin{tabular}{|c|c|c|c|c|c|c|}
\hline $\begin{array}{l}\text { Project } \\
\text { portfolio }\end{array}$ & Ranking & $\begin{array}{l}\text { Composition of the } \\
\text { project portfolio }\end{array}$ & $\begin{array}{l}\text { Investment in the } \\
\text { operation period }\end{array}$ & $\begin{array}{l}\text { Investment in the } \\
\text { construction period }\end{array}$ & $\begin{array}{l}\text { Number of } \\
\text { employees }\end{array}$ & $\begin{array}{l}\text { Portfolic } \\
\text { income }\end{array}$ \\
\hline \multirow{3}{*}{1} & \multirow{3}{*}{1} & 1 & 10000 & 17600 & 1100 & \multirow{3}{*}{20101} \\
\hline & & 2 & 100000 & 25000 & 200 & \\
\hline & & 3 & 10000 & 15800 & 200 & \\
\hline \multirow{3}{*}{2} & \multirow{3}{*}{3} & 1 & 10000 & 17600 & 900 & \multirow{3}{*}{10678} \\
\hline & & 2 & 100000 & 25000 & 200 & \\
\hline & & 4 & 10000 & 24000 & 200 & \\
\hline \multirow{3}{*}{3} & \multirow{3}{*}{2} & 1 & 10000 & 17600 & 1400 & \multirow{3}{*}{14795} \\
\hline & & 3 & 25000 & 15800 & 200 & \\
\hline & & 4 & 85000 & 24000 & 200 & \\
\hline \multirow{3}{*}{4} & \multirow{3}{*}{4} & 2 & 30592 & 25000 & 1400 & \multirow{3}{*}{9261} \\
\hline & & 3 & 14704 & 15800 & 200 & \\
\hline & & 4 & 74704 & 24000 & 200 & \\
\hline
\end{tabular}

\section{Conclusion}

In this paper, the interaction effect MCGP model is constructed to solve the problem of portfolio evaluation, considering the interaction effect between projects. The results of example analysis show that the interaction effect MCGP model can better evaluate the two-project portfolio and three-project portfolio. It is found that in comparison with the DEA method, the interaction effect MCGP model has a better ability to distinguish the project portfolio. The project portfolio selection method proposed in this study takes into consideration the complex interaction relationship within the project portfolio, which makes up for the deficiency of interaction relationship analysis in the existing project portfolio selection research, provides a basis for enterprises to measure the complex relationship within the project portfolio, and also provides new methods and ideas for enterprise project portfolio selection.

\section{Data Availability}

The experimental data used to support the findings of this study are included within the article.

\section{Conflicts of Interest}

The authors declare that they have no conflicts of interest.

\section{Acknowledgments}

This work was supported by the Jiangsu University Philosophy and social science research project "Research on the co-evolution of innovation ecosystem in the era of digital economy in Jiangsu Province".

\section{References}

[1] V. Korotkov and D. Wu, "Evaluating the quality of solutions in project portfolio selection," Omega, vol. 91, pp. 1-13, 2019.

[2] A. F. Carazo, "Multi-Criteria project portfolio selection," in Handbook on Project Management and Scheduling Volume 2, pp. 709-728, Springer International Publishing, Berlin, Germany, 2015.
[3] H. Markowitz, "Portfolio selection," The Journal of Finance, vol. 7, no. 1, pp. 77-91, 1952.

[4] J. H. Lorie and L. J. Savage, "Three problems in rationing capital," The Journal of Business, vol. 28, no. 4, pp. 229-339, 1955.

[5] R. S. Arifin, S. S. Moersidik, E. T. B. Soesilo, D. M. Hartono, and Y. Latief, "Dynamic project interdependencies (PI) in optimizing project portfolio management (PPM)," International Journal of Technology, vol. 6, no. 5, pp. 828-837, 2015.

[6] R. Santhanam and J. Kyparisis, "A multiple criteria decision model for information system project selection," Computers \& Operations Research, vol. 22, no. 8, pp. 807-818, 1995.

[7] W. L. Jin and S. H. Kim, "Using analytic network process and goal programming for interdependent information system project selection," Computers \& Operations Research, vol. 27, no. 4, pp. 367-382, 2000.

[8] M. A. Badri and D. Davis, "A comprehensive 0-1 goal programming model for project selection," International Journal of Project Management, vol. 19, no. 4, pp. 243-252, 2012.

[9] M. Nowak, "Project portfolio selection using interactive approach," Procedia Engineering, vol. 57, pp. 814-822, 2013.

[10] K. Khalili-Damghani, S. Sadi-Nezhad, and M. Tavana, "Solving multi-period project selection problems with fuzzy goal programming based on TOPSIS and a fuzzy preference relation," Information Sciences, vol. 252, pp. 42-61, 2013.

[11] A. F. Czajkowski and S. Jones, "Selecting interrelated R\&D projects in space technology planning," IEEE Transactions on Engineering Management, vol. EM-33, no. 1, pp. 17-24, 1986.

[12] R. L. Schmidt, "A model for R\&D project selection with combined benefit, outcome and resource interactions," IEEE Transactions on Engineering Management, vol. 40, no. 4, pp. 403-410, 1993.

[13] W. L. Jin and S. H. Kim, "An integrated approach for interdependent information system project selection," International Journal of Project Management, vol. 19, no. 2, pp. 111-118, 2001.

[14] J. Klapka and P. Piňos, "Decision support system for multicriterial R\&D and information systems projects selection," European Journal of Operational Research, vol. 23, no. 140, pp. 609-618, 2002.

[15] R. Santhanam and G. J. Kyparisis, "A decision model for interdependent information system project selection," European Journal of Operational Research, vol. 89, no. 2, pp. 380-399, 1996.

[16] C. Stummer and K. Heidenberger, "Interactive R\&D portfolio analysis with project interdependencies and time profiles of 
multiple objectives," IEEE Transactions on Engineering Management, vol. 50, no. 2, pp. 175-183, 2003.

[17] K. F. Doerner, W. J. Gutjahr, R. F. Hartl, C. Strauss, and C. Stummer, "Pareto ant colony optimization with ILP preprocessing in multiobjective project portfolio selection," European Journal of Operational Research, vol. 171, no. 3, pp. 830-841, 2006.

[18] H. Eilat, B. Golany, and A. Shtub, "Constructing and evaluating balanced portfolios of R\&D projects with interactions: a DEA based methodology," European Journal of Operational Research, vol. 172, no. 3, pp. 1018-1039, 2006.

[19] M. Rabbani, M. Aramoon Bajestani, and G. Baharian Khoshkhou, "A multi-objective particle swarm optimization for project selection problem," Expert Systems with Applications, vol. 37, no. 1, pp. 315-321, 2010.

[20] T. J. Stewart, "Multiple objective project portfolio selection based on reference points," Journal of Business Economics, vol. 86, no. 1-2, pp. 23-33, 2016.

[21] S. Reiter, Choosing an Investment Program among Interdependent Projects, Macmillan Education, London, UK, 1973.

[22] H. M. Weingartner, "Capital budgeting of interrelated projects: survey and synthesis," Management Science, vol. 12, no. 7, pp. 485-516, 1966.

[23] T. E. Gear and G. C. Cowie, "A note on modeling project interdependence in research and development," Decision Sciences, vol. 11, no. 4, pp. 738-748, 1980.

[24] J. F. Bard, R. Balachandra, and P. E. Kaufmann, "An interactive approach to R\&D project selection and termination," IEEE Transactions on Engineering Management, vol. 35, no. 3, pp. 139-146, 1988.

[25] C.-T. Chang, "Multi-choice goal programming," Omega, vol. 35, no. 4, pp. 389-396, 2007.

[26] C.-T. Chang, "Revised multi-choice goal programming," Applied Mathematical Modelling, vol. 32, no. 12, pp. 25872595, 2008.

[27] F. Zhou, X. Wang, M. Goh, L. Zhou, and Y. He, "Supplier portfolio of key outsourcing parts selection using a two-stage decision making framework for Chinese domestic automaker," Computers \& Industrial Engineering, vol. 128, pp. 559-575, 2019.

[28] H. Amin, Z.-Y. Zhuang, K. Noureddine, and D.-C. Li, "Weighted-additive fuzzy multi-choice goal programming (WA-FMCGP) for supporting renewable energy site selection decisions," European Journal of Operational Research, vol. 285, no. 2, pp. 642-654, 2020.

[29] S.-Y. Wang, W.-M. Chen, and Y. Liu, "Collaborative product portfolio design based on the approach of multi choice goal programming," Mathematical Problems in Engineering, vol. 2021, Article ID 6678533, 16 pages, 2021.

[30] -Y. Wang, W.-M. Chen, R. Wang, and X.-L. Wu, "Multiobjective evaluation of co-evolution among innovation populations based on Lotka-Volterra Equilibrium," Discrete Dynamics in Nature and Society, vol. 2021, Article ID 5569108, 14 pages, 2021.

[31] L. Schrage, LINGO Release 8.0, LINDO System, Inc., Chicago, IL, USA, 2002.

[32] K. Khalili-Damghani, S. Sadi-Nezhad, F. H. Lotfi, and M. Tavana, "A hybrid fuzzy rule-based multi-criteria framework for sustainable project portfolio selection," Information Sciences, vol. 220, pp. 442-462, 2013.

[33] Y. Wu, C. Xu, Y. Ke, K. Chen, and X. Sun, "An intuitionistic fuzzy multi-criteria framework for large-scale rooftop PV project portfolio selection: case study in Zhejiang, China," Energy, vol. 143, pp. 295-309, 2018.
[34] G. S. Pavlak, G. P. Henze, and V. J. Cushing, "Evaluating synergistic effect of optimally controlling commercial building thermal mass portfolios," Energy, vol. 84, no. 5, pp. 161-176, 2015.

[35] D. Guan, P. Guo, and K. W. Hipel, "Risk reduction in a project portfolio," Journal of Systems Science and Systems Engineering, vol. 26, no. 1, pp. 3-22, 2017. 